\title{
Avaliação da dinâmica de ocupação da terra em Salinópolis/PA com base no modelo Pressão-Estado-Impacto-Resposta (PEIR)
}

A configuração socioespacial de uma região é influenciada por pressões que estimulam ou desestimulam a ocupação em função dos interesses da população envolvida. Esse processo é definido tanto por situações atuais quanto pelo processo histórico de ocupação. A identificação dos fatores que definem esse processo é importante para a verificação de tendências, possibilitando verificar as respostas da ocupação do território. Nesse sentido, esta pesquisa busca identificar quais as principais variáveis que explicam a configuração do ordenamento territorial do município de Salinópolis. Para isso, foram realizadas análises do histórico de ocupação da região, obtida por estudo bibliográfico, da variação espaço-temporal da ocupação da área de estudo e da percepção da população acerca das áreas preferenciais do município e seus principais motivadores, obtida pela aplicação de questionários. A análise final e a identificação das variáveis foram realizadas pela aplicação do modelo Pressão-Estado-Impacto-Resposta (PEIR). Os resultados preliminares indicaram que as principais variáveis que explicam a dinâmica de ocupação em Salinópolis são: distância ao mar; distância às rodovias PA-444 e PA-124; densidade de malha viária; distância às áreas de maior especulação imobiliária; grau de implantação de empreendimentos; distância às manchas urbanas consolidadas; distância às áreas de menor especulação imobiliária; e distância ao centro comercial.

Palavras-chave: Configuração socioespacial; Variáveis explicativas; Dinâmica de ocupação.

\section{Dynamics evaluation of land occupation in Salinópolis/PA based on the Pressure-State-Impact-Response (PSIR) model}

\begin{abstract}
The socio-spatial configuration of a region is influenced by factors that presures occupation according to the interests of the population involved. This process is defined both by current situations and by the history of occupation. The identification of the factors that define this process is important for verifying trends, and the occupation response of the territory. In this sense, this research seeks to identify the main variables that explain the territorial ordering in the municipality of Salinópolis. For this, were realized analyzes of the region's occupation history, obtained through a bibliographic study, of the spatio-temporal variation in the occupation of the study area, and of the population's perception of the preferred areas of the municipality and their main motivators, obtained by applying questionnaires. The final analysis and identification of the variables was realized by applying the Pressure-State-Impact-Response (PSIR) model. The preliminary results indicated that the main variables that explain the dynamics of occupation in Salinopolis are: distance to the sea; distance to the PA-444 and PA-124 highways; road mesh density; distance to areas of greater real estate speculation; degree of implementation of projects; distance to consolidated urban patches; distance to areas of less real estate speculation; and distance to the center.
\end{abstract}

Keywords: Socio-spatial configuration; Explanatory variables; Occupation dynamics.

Topic: Desenvolvimento, Sustentabilidade e Meio Ambiente

Reviewed anonymously in the process of blind peer
Received: 02/07/2021

Approved: 28/07/2021
Amanda Gama Rosa (iD

Universidade Federal do Pará, Brasil

http://lattes.cnpq.br/0895837333331224

http://orcid.org/0000-0002-9053-2777

amandagamarosa@gmail.com

Milena Marília Nogueira de Andrade (ic

Universidade Federal Rural da Amazônia, Brasil

http://lattes.cnpq.br/1930321094483005

https://orcid.org/0000-0001-5799-7321

milena.andrade@ufra.edu.br

Cézar Di Paula da Silva Pinheiro

Instituto Tecnológico Vale, Brasil

http://lattes.cnpq.br/9477837707374728

http://orcid.org/0000-0003-3946-2379

cezarpinheiroo@hotmail.com
Adriano Marlison Leão de Sousa (iD)

Universidade Federal Rural da Amazônia, Brasil

http://lattes.cnpq.br/4371199443425884

http://orcid.org/0000-0002-2809-5318

adriano.souza@ufra.edu.br
Referencing this:

ROSA, A. G.; ANDRADE, M. M. N.; PINHEIRO, C. P. S.; SOUSA, A. M. L., Avaliação da dinâmica de ocupação da terra em Salinópolis/PA com base no modelo Pressão-Estado-Impacto-Resposta (PEIR). Revista Ibero Americana de Ciências Ambientais, v.12, n.7, p.414-432, 2021. DOI: http://doi.org/10.6008/CBPC2179-6858.2021.007.0037 


\section{INTRODUÇÃO}

Constantemente os ambientes naturais são modificados e usados para o processo de expansão humana, resultando em implicações sociais e ambientais que podem influenciar diretamente em situações de impacto e risco, tendo em vista a forma acelerada e deficiente de expansão (SALLES et al., 2013). A expansão urbana de cidades litorâneas é reconhecida por ter uma possibilidade de usos múltiplos do espaço e dos recursos naturais. Geralmente, a dinâmica da ocupação dessas áreas, extremamente frágeis às ações humanas, acompanha os ciclos econômicos e seus interesses (MELLO et al., 2013). Essa forma de expansão gera efeitos, como segregação socioespacial, fragmentação, ampliação de áreas de risco e impactos ambientais associados a resíduos e efluentes (ANTOCHEVIZ, 2017).

No nordeste do estado do Pará, efeitos da expansão urbana começaram a ser observados na década de 60, quando a Amazônia foi inserida no modelo desenvolvimentista e a região passou a receber investimentos, especialmente no setor de transportes, a fim de estabelecer um desenvolvimento socioeconômico e a integração nacional (AREND et al., 2012). Exemplos dessas medidas foram os Planos Nacionais de Desenvolvimento, a Empresa Brasileira de Turismo (EMBRATUR) e o Plano de Integração Nacional (PIN) (ALMEIDA, 2017).

Nesse mesmo contexto histórico e espacial, o município de Salinópolis, transformando-se em Estância Hidromineral (Decreto/Lei 3.786/66), passou a receber investimentos do Estado em infraestruturas e incentivo ao turismo. A partir da década de 1970 se intensifica a urbanização no município, sem instrumentos de ordenamento territorial, avançando principalmente sobre a ilha do Atalaia, visto a construção da estrada PA-444 e da ponte que a interliga à sede do município, no ano de 1974 (RANIERI et al., 2015; ALMEIDA, 2017).

Salinópolis, atualmente, tem o ambiente marcado pelo desenvolvimento ligado ao mercado turístico, setor muito forte na região. Essa questão reflete na ocupação próxima e sobre a linha de costa, sobre manguezais e campos de dunas, inclusive por grandes empreendimentos, loteamentos, resorts e parques aquáticos. Isto tem causado impactos ambientais, sociais e econômicos, a exemplo de ocupação de áreas de risco à inundação de maré e erosão costeira, contaminação do lençol freático, destinação incorreta de resíduos sólidos e recuo de estruturas (pousadas, restaurantes e residências) na linha de costa (RANIERI et al., 2016; BRAGA et al., 2019).

Tais fatores são grandes influenciadores da dinâmica de ocupação desse espaço litorâneo e, ao serem analisados, podem revelar tendências e padrões de ocupação do território (MELLO et al., 2013). Daí vem a importância em compreender a dinâmica de modificação do espaço, especialmente os litorâneos, como no caso de Salinópolis, tendo em vista a possibilidade de auxiliar o ordenamento territorial e evitar habitações inadequadas e em áreas de risco.

Essa compreensão pode se dar pelo entendimento das pressões, do estado, dos impactos e respostas de cada contexto local, servindo como diagnóstico para o entendimento da dinâmica de ocupação do município em questão, bem como da relação de causa-efeito das atividades humanas e consequências 
espaciais, sociais e econômicas (SOUSA-FELIX et al., 2017).

Diante disso, esta pesquisa busca realizar uma análise da dinâmica de ocupação costeira no município de Salinópolis/PA de forma integrada sob a ótica do modelo Pressão-Estado-Impacto-Resposta (PEIR).

\section{MATERIAIS E MÉTODOS}

\section{Área de estudo}

A área de estudo está inserida no município de Salinópolis, localizado no nordeste do estado do Pará, e engloba a área urbanizada e a orla marítima do município (Figura 1). A área total é de aproximadamente $75,9 \mathrm{~km}^{2}$ limitada pelas coordenadas $0^{\circ} 36^{\prime} / 0^{\circ} 48^{\prime} \mathrm{S}$ e $47^{\circ} 15^{\prime} / 47^{\circ} 24^{\prime} \mathrm{W}$, e abrigando uma população de cerca de 40.922 habitantes, de acordo com estimativas para o ano de 2020 (IBGE, 2020). O turismo é a principal atividade econômica do município, estimulado pelo grande potencial paisagístico local das praias do Atalaia, Farol Velho, Maçarico e Corvina; e uma forte vertente da dinâmica de ocupação do município incentivado historicamente pelo Governo do Estado (SOUZA et al., 2018).

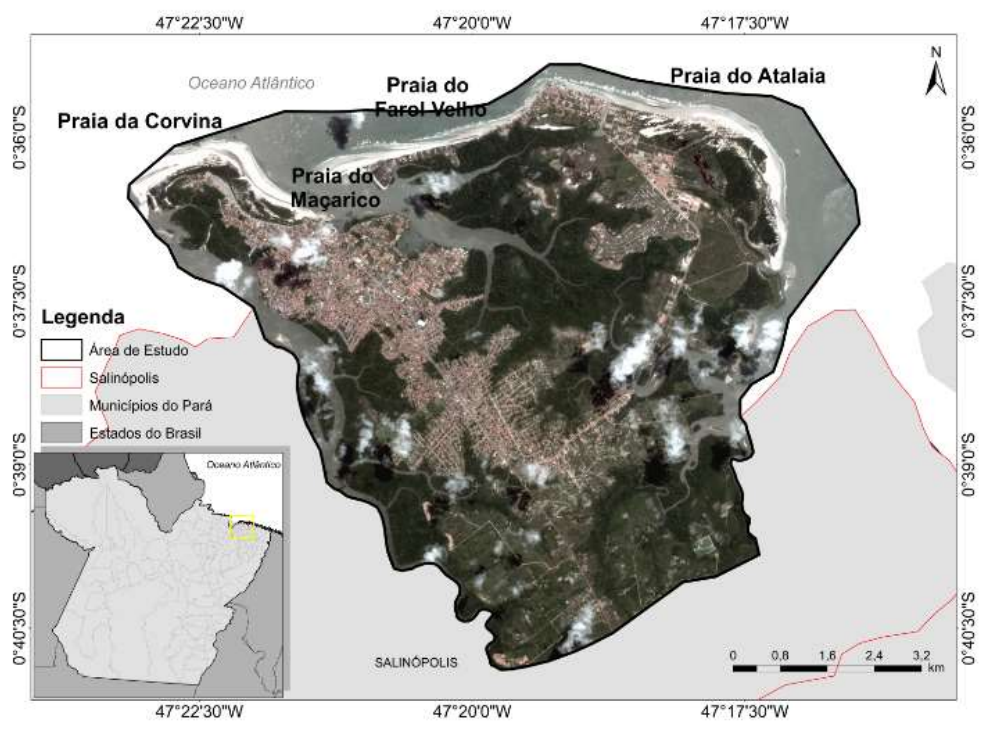

Figura 1: Localização da área de estudo. (Imagem PlanetScope, ano 2018, composição R3G2B1, resolução espacial 3 metros, projeção geográfica, Datum SIRGAS 2000).

A sede do município está localizada no centro-oeste da área de estudo, que apresenta hoje a região mais populosa do município de Salinópolis, próxima às praias do Maçarico e Corvina. A região central, nas proximidades da praia do Farol Velho, evidencia uma urbanização mais próxima da costa, enquanto que o Leste, representado pela praia do Atalaia e banco de dunas, se observa uma urbanização em expansão (RANIERI et al., 2015).

O processo de urbanização atual em direção à linha de costa tem avançado sobre áreas de manguezais e campos de dunas o que causa impactos ambientais como: redução de áreas naturais, degradação de ecossistemas, erosão costeira e ocupação de áreas impróprias e periféricas pela população local (RANIERI et al., 2016; BRAGA et al., 2019; PINHEIRO et al., 2020). 


\section{Métodos}

As etapas desenvolvidas neste trabalho foram: aquisição de dados, estudo bibliográfico, análise espaço-temporal, aplicação de questionários e entrevistas, e aplicação do modelo PEIR. Os dados usados como base inicialmente para a análise da dinâmica de ocupação foram os estudos bibliográfico acerca do histórico de ocupação no município. O estudo bibliográfico focou na aquisição de dados sobre os acontecimentos históricos que influenciaram na ocupação do território, principalmente a partir da década de 1930. Com os resultados, foi montada uma tabela com a linha dos tempos dos principais eventos.

A análise espacial da área de estudo se deu através da classificação da ocupação da terra dos anos de 2010, 2014 e 2018. Para isto, realizou-se a classificação orientada a objeto pelo método Geographic Object-Based Image Analisys (GEOBIA) (BAATZ et al., 2004; ALVES et al., 2009) em imagens de alta resolução espacial. Para o ano de 2010 foram usadas imagens do satélite SPOT-5 (Sallite Pour I'Observation de la Terre), com resolução espacial de 10 metros, do dia 26 de junho de 2010 (GLEYZES et al., 2003). Para 2014, as imagens utilizadas foram provenientes dos satélites RapidEye dos dias 26 de junho e 01 de agosto de 2014, com resolução espacial de 5 metros (RAPIDEYE, 2016). Enquanto que, para o ano de 2018, as imagens foram dos satélites PlanetScope, provenientes da plataforma PLANET, que apresentam resolução especial de 3 metros (PLANET, 2019). A data das imagens é 07 de junho de 2018. Para melhorar a qualidade das imagens foram inseridas informações texturais provenientes do cálculo do Índice de Vegetação Ajustado ao Solo (SAVI) (HUETE, 1988). Esse método envolveu, inicialmente, o processo segmentação das imagens pelo método de crescimento de regiões de Baatz (BAATZ et al., 2000). Para a classificação foi utilizado o algoritmo C5.0 Decision Trees na plataforma GeoDMA do software TerraView 5.3.3. A classes definidas foram: Área Urbana (áreas pavimentadas, construções e solo exposto); Faixa de Praia; Dunas; Vegetação Densa (florestas); Vegetação Não Densa (restinga, capoeira e campos naturais); e; Corpo D’água (mar, rios e lagoas). A avaliação da classificação foi realizada para a imagem de 2018, visto que apenas neste ano foi possível executar a validação, que contou com a amostragem de 50 pontos por classe, divididos em pontos de Verdade Terrestre - em campo - e pontos observados em imagens do Google Earth Pro georreferenciadas, conforme aplicado por Wiggers e Ribeiro (2015). Essa avaliação foi feita por Matriz de Confusão, a partir da qual foram calculados os índices de Exatidão Global e o índice Kappa, de acordo com Congalton e Green (2009).

As entrevistas foram aplicadas para três grupos distintos na área de estudo, buscando englobar a heterogeneidade das opiniões e interesses na região. Dentre os três grupos, dois foram de informantes-chave no município: representantes da prefeitura que lidam com o ordenamento territorial (três funcionários das Secretarias Municipais de Meio Ambiente, de Obras e de Turismo), a fim de compreender os rumos da política atual que influenciam na ocupação da terra e; um funcionário do cartório do único ofício do município, com o objetivo de entender o histórico da dinâmica de transações, desmembramentos do território e inserção de loteamentos. O outro grupo de entrevistados foi a população residente do município.

A amostragem para os grupos de informantes-chave foi intencional não probabilística. Esse tipo de 
amostragem é utilizado quando uma amostra é escolhida “propositalmente" porque apresenta característica que se acredita que sejam confiáveis para explicar um fenômeno (GOODE et al., 1979). Nessa técnica se dá ampla liberdade de escolha ao entrevistador (BARROS et al., 1997).

Para as entrevistas realizadas com a população residente a amostragem foi aleatória simples, método probabilístico, onde cada membro da população teve chance igual e independente de ser selecionado (ZAR, 1996). Foram realizadas 396 entrevistas, tendo em vista o tamanho da população estimada para o ano de 2017 pelo IBGE (IBGE, 2020). Considerou-se o erro amostral de 5\%. Foram realizadas duas campanhas de aplicação de questionários em diferentes setores dentro da área de estudo. A primeira coleta de dados ocorreu em março de 2019 e a segunda em agosto do mesmo ano.

Os questionários foram estruturados com questões quali-quantitativas, semiestruturadas para os informantes-chave e estruturados para a população, orientados para a compreensão dos fluxos de ocupação e para o grau de implantação dos empreendimentos. Na última etapa, os dados obtidos foram tabulados em planilha Excel e demonstrados na forma quantitativa. Para a tabulação dos dados resultantes das entrevistas semiestruturadas com os informantes-chave, realizou-se a padronização das respostas a partir do objeto central do questionamento, possibilitando a sua apresentação qualitativa. As questões dos questionários aplicados aos representantes da prefeitura e à população fixa foram divididas em blocos temáticos, orientados para uma melhor observação e análise dos resultados (Quadro 1).

Quadro 1: Blocos temáticos para apresentação e análise dos resultados dos questionários.

\begin{tabular}{|c|c|c|}
\hline BLOCO & TEMA & PERGUNTAS \\
\hline \multicolumn{3}{|c|}{ Questionários aplicados à população fixa } \\
\hline Bloco 1 & Formação socioespacial & $\begin{array}{l}\text { Há quantos anos é morador do município? Qual o período de aquisição do espaço em uso? Qual era o } \\
\text { ambiente existente na aquisição do espaço em uso? Houve orientação técnica ou fiscalização } \\
\text { ambiental por parte dos órgãos competentes durante o processo de aquisição? Qual o motivo de } \\
\text { aquisição do espaço em uso no município? }\end{array}$ \\
\hline Bloco 2 & $\begin{array}{l}\text { Tendência de Ocupação } \\
\text { Atual }\end{array}$ & $\begin{array}{l}\text { Qual o bairro/região de moradia? Qual o motivo de aquisição desse espaço em seu bairro? Pretende } \\
\text { se mudar para outro bairro/região? Qual? Por quê? Durante o processo de ocupação do município, } \\
\text { você percebeu preferência por quais regiões? A seu ver, quais fatores têm influenciado a preferência } \\
\text { por essas regiões? }\end{array}$ \\
\hline Bloco 3 & Aspectos Ambientais & $\begin{array}{l}\text { Você observou mudanças no ambiente desde o período estabelecido no município? Se sim, quais as } \\
\text { principais mudanças no ambiente observadas? }\end{array}$ \\
\hline \multicolumn{3}{|c|}{ Questionários aplicados aos representantes da prefeitura } \\
\hline Bloco 1 & $\begin{array}{l}\text { Caracterização } \\
\text { populacional }\end{array}$ & $\begin{array}{l}\text { Qual a população flutuante aproximada? Qual o percentual aproximado de residências e } 2^{\circ} \\
\text { residências? }\end{array}$ \\
\hline Bloco 2 & $\begin{array}{l}\text { Tendência de Ocupação } \\
\text { Atual }\end{array}$ & $\begin{array}{l}\text { Quais as regiões de maior preferência pelas populações flutuante e permanente? Quais as regiões de } \\
\text { maior e menor especulação imobiliária? Houve algum acontecimento que alterou a dinâmica de } \\
\text { ocupação urbana nos últimos } 15 \text { anos? } \\
\text { Com a construção da PA-444, observou-se alterações: no mercado imobiliário? Nos costumes? Na } \\
\text { migração? Existem projetos de novas obras de urbanização a serem realizadas no município? Existem } \\
\text { projetos de grandes empreendimentos privados a serem instalados no município? }\end{array}$ \\
\hline Bloco 3 & $\begin{array}{l}\text { Diretrizes, Instrumentos } \\
\text { Legais e Trâmites para a } \\
\text { Ocupação }\end{array}$ & $\begin{array}{l}\text { Quais as diretrizes para ocupação da zona costeira do município? Quais os instrumentos legais de } \\
\text { gestão costeira no município? Quais os trâmites e restrições impostos pela prefeitura à construção de } \\
\text { empreendimentos litorâneos? }\end{array}$ \\
\hline Bloco 4 & Aspectos Ambientais & $\begin{array}{l}\text { Existe algum plano de Unidade de Conservação? Quais os principais problemas da ocupação costeira } \\
\text { identificados pela prefeitura? }\end{array}$ \\
\hline
\end{tabular}

A análise geral e integradora foi feita utilizando a teoria do Modelo PEIR. Este é uma ferramenta que combina feições qualitativas e quantitativas de interações sociais, econômicas e ambientais (SOUSA-FELIX et al., 2017; OECD, 1993; EEA, 1995). A ferramenta PEIR também tem como objetivo prover abordagens qualitativas de análise e possibilita a associação entre as variáveis relevantes dos resultados dos questionários, da análise espaço-temporal das imagens de satélite, do estudo do histórico de ocupação do 
município e a das verificações em campo.

A aplicação da ferramenta PEIR ocorreu em quatro etapas: interpretação das pressões; descrição do estado atual; descrição dos impactos; e avaliação da resposta da sociedade (SOUSA-FELIX et al., 2017; PINTO et al., 2013; GARI et al., 2015). Para interpretar as pressões, a análise incluiu os processos e atividades que podem implicar no deslocamento de moradia da população local, na implantação de grandes obras e empreendimentos e na ocupação de áreas impróprias. A descrição do estado atual se deu pela análise espacial da área e pelas evidências registradas em campo. Os impactos foram descritos a partir da identificação dos efeitos diretos e indiretos das atividades locais. E a resposta foi o resultado da ação da população local, do setor de turismo e do governo frente às pressões, estado e impacto.

\section{RESULTADOS E DISCUSSÃO}

Os resultados foram divididos em quatro partes. A primeira delas refere-se a uma descrição da ocupação histórica do município de Salinópolis através de uma linha temporal dos eventos principais, a segunda apresenta os principais resultados da análise espaço-temporal dos últimos 10 anos, a terceira discorre sobre as entrevistas aplicadas aos três grupos de interesse e a quarta, por sua vez, apresenta a análise geral com aplicação do modelo PEIR e as variáveis identificadas como de maior influência da dinâmica de ocupação.

\section{Estudo bibliográfico}

A ocupação humana na zona costeira do nordeste paraense tem seus indícios em 5.000 anos atrás, com base em estudos e evidências arqueológicas, com marco no século XVII através do fomento mercantilista da Companhia de Comércio do Grão-Pará e Maranhão e do Sistema de Capitanias Hereditárias, que contribuíram para a ocupação humana no litoral amazônico (FURTADO et al., 2002; FURTADO, 2011). Entretanto, foi a partir do século XX que começaram a ser percebidas mudanças nas relações entre o homem e o ambiente costeiro do estado do Pará (SANTANA, 2011).

No município de Salinópolis, efeitos da ocupação humana começaram a ser evidenciados a partir da década de 1930 e, desde então, acontecimentos foram marcando a dinâmica populacional, década após década (CAVALCANTE, 2001; BRITO, 2004; MARINHO, 2009; RANIERI, 2014; ALMEIDA, 2017) (Quadro 2).

Quadro 2: Momentos históricos da ocupação humana no município de Salinópolis.

\begin{tabular}{|l|l|}
\hline $\begin{array}{l}\text { Linha do } \\
\text { tempo }\end{array}$ & Acontecimentos \\
\hline 1930 & $\begin{array}{l}\text { - Inauguração do primeiro hotel da região, em 1936 (Hotel Atlântico - hoje conhecido como Hotel Salinópolis). } \\
\text { - Conclusão da estrada Capanema-Salinópolis (PA-124), em 1937, intensificando a procura às praias e transformando o município } \\
\text { em um importante balneário. }\end{array}$ \\
\hline 1940 & $\begin{array}{l}\text { - Criação do Fundo Rodoviário dos Estados e Municípios (Decreto-Lei N 2.615/40), que levou ao desenvolvimento rodoviário na } \\
\text { região amazônica. } \\
\text { - Início do funcionamento de algumas linhas de ônibus entre Salinópolis e Belém, em viagens de aproximadamente 15 horas. }\end{array}$ \\
\hline 1950 & $\begin{array}{l}\text { - Aumento do acesso aos ambientes costeiros, que antes se dava principalmente por via marítima e fluvial (devido a } \\
\text { comunicações terrestres precárias), com a expansão das rodovias de acesso de territórios praieiros de domínio da população } \\
\text { nativa e pescadores artesanais do nordeste do Pará. }\end{array}$ \\
\hline & $\begin{array}{l}\text { - Inauguração da rodovia Belém-Brasília (BR-10), sendo o primeiro elo da Amazônia com o centro-sul. } \\
\left.- \text { Transformação do município em Estância Hidromineral (Lei N }{ }^{\circ} 3.786 / 66\right), \text { incorporando a região à economia nacional e trazendo } \\
\text { investimentos em infraestrutura, políticas públicas de desenvolvimento socioeconômico e incentivo ao turismo. } \\
- \text { Criação da Empresa Brasileira de Turismo (EMBRATUR) em 1966, para fins de incentivo turístico e de mostrar uma imagem }\end{array}$ \\
\hline
\end{tabular}




\begin{tabular}{|c|c|}
\hline & $\begin{array}{l}\text { positiva do país no exterior, que estava comprometida no cenário internacional devido ao regime militar. } \\
\text { - Incentivo do Estado a partir de doação de terras públicas. } \\
\text { - Criação da estrada que liga a sede do município à praia do Maçarico, contribuindo para a devastação de boa parte da vegetação } \\
\text { nativa litorânea e de dunas. }\end{array}$ \\
\hline 1970 & $\begin{array}{l}\text { - Construção da PA-444 e da ponte que liga a sede municipal à ilha do Atalaia, em 1973, intensificando a urbanização, especulação } \\
\text { imobiliária e atividade turística. } \\
\text { - Pavimentação da PA-324, que liga o município de Santa Maria do Pará ao de São João de Pirabas (limítrofe à Salinópolis). } \\
\text { - Implantação do Projeto AGRISAL (Agroindustrial de Salinópolis S/A), um importante projeto econômico apoiado pelo Estado, em } \\
\text { uma área de mais de } 10.000 \text { hectares, com o objetivo de diversificar a economia do município, inserindo a produção agrícola }\end{array}$ \\
\hline 1980 & $\begin{array}{l}\text { - A Constituição Federal Brasileira de 1988, em seu artigo 180, legitima o turismo como força motriz de desenvolvimento social e } \\
\text { econômico, inaugurando uma nova fase das políticas públicas e sociais. } \\
\text { - Desativação do Projeto AGRISAL e consequente liberação das áreas do projeto, levando a um acelerado crescimento da malha } \\
\text { urbana. } \\
\text { - Crescente aparecimento de bairros no município em áreas que anteriormente pertenciam a AGRISAL, que geralmente } \\
\text { ocorreram de forma irregular, a exemplo de Jaderlândia, São Tomé, São José, Atlântico I e II, Pedrinhas, Nova Brasília e Bairro da } \\
\text { Ponte. }\end{array}$ \\
\hline 1990 & $\begin{array}{l}\text { - Implementação do projeto político do governo estadual denominado de "Novo Pará", com início em 1994, destinando pesados } \\
\text { investimentos para o desenvolvimento do turismo na cidade. } \\
\text { - Crescimento de "segundas residências", levando ao surgimento de bairros elitizados. } \\
\text { - Estabelecimento da política de incentivo às atividades produtivas no estado, incluindo a "indústria do turismo" (Lei N } 5.943 / 96) \text {. }\end{array}$ \\
\hline 2000 & $\begin{array}{l}\text { - Construção do Complexo Turístico Orla do Maçarico para atender a população visitante (financiada pelo projeto Novo Pará). } \\
\text { - Urbanização da Praia do Atalaia. } \\
\text { - Estabelecimento de grandes empreendimentos imobiliários na ilha do Atalaia. } \\
\text { - Serviços de conservação das rodovias PA-324 e PA-124 recebidos da Secretaria Executiva de Transportes (SETRAN). }\end{array}$ \\
\hline 2010 & $\begin{array}{l}\text { - Intensa urbanização da ilha do Atalaia. } \\
\text { - Construção de resorts e parques aquáticos. } \\
\text { - Duplicação da PA-444. } \\
\text { - Ampliação e reforma do Aeródromo de Salinópolis. }\end{array}$ \\
\hline
\end{tabular}

De acordo com Brito (2004), os principais fatores que influenciaram o início da expansão urbana na cidade foram a doação de terras públicas pelo governador Alacid Nunes, a construção da segunda residência oficial do governador do Estado do Pará, o desenvolvimento da infraestrutura, a construção de segundas residências e o projeto AGRISAL.

Esses acontecimentos e a implementação de políticas públicas, principalmente a partir da segunda metade do século XX, foram grandes influências para o uso e ocupação do município, gerando uma pressão que acabou sendo intensificada nos últimos anos, com a potencialização da urbanização principalmente na ilha do Atalaia e nas margens da PA-444 e implantação de obras urbanas e empreendimentos, funcionando como um atrativo tanto para a população flutuante, foco das principais implantações de infraestrutura local, como para a população local, em busca de oferecer atividades de comércio e serviços para o público turístico (RANIERI, 2014; ALMEIDA, 2017).

O contexto de Salinópolis, que foi baseado em diversos acontecimentos históricos de forte indução à ocupação e urbanização direcionada ao turismo, mantém esse ritmo atualmente, comprovado pelos acontecimentos da década de 2010. Hoje, parte da população residente é atraída para bairros centrais e áreas próximas às praias com a finalidade de prestação de produtos e serviços aos visitantes, como mencionado anteriormente, enquanto outra parte dessa população é afastada dessas regiões por conta da especulação imobiliária.

\section{Análise espaço-temporal dos últimos 10 anos}

A análise espaço-temporal da ocupação da terra na área de estudo, apresenta grande evidência de avanço da urbanização entre os anos de 2010, 2014 e 2018, tanto em direção ao continente como em direção à costa, principalmente sobre a ilha do Atalaia (Figura 2), região onde mais se tem observado expansão em 
virtude do mercado turístico (RANIERI et al., 2015; BRAGA et al., 2019). Essa tendência é confirmada na

Tabela 1, onde se apresenta, numericamente, a variação das áreas das classes de ocupação da terra ao longo dos anos de análise.
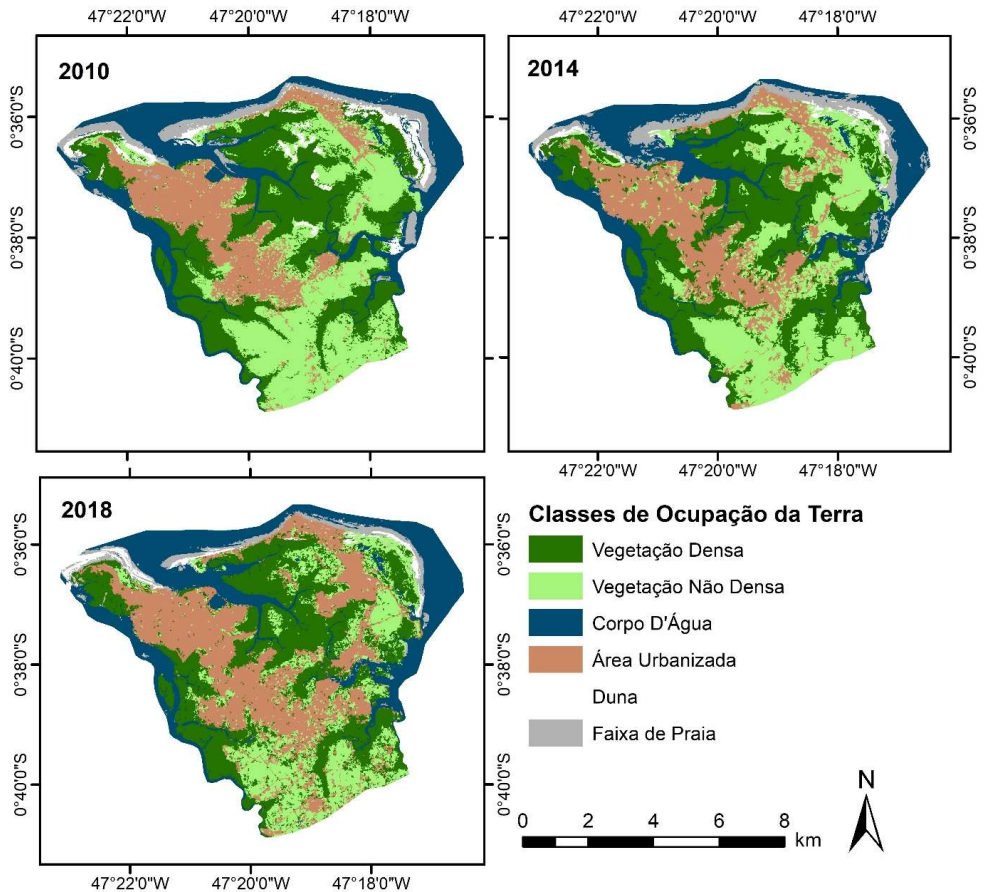

Figura 2: Classificação de ocupação da terra em Salinópolis nos anos de 2010, 2014 e 2018.

Tabela 1: Variação da área das classes de ocupação da terra entre os anos de 2010, 2014 e 2018.

\begin{tabular}{|c|c|c|c|c|c|c|}
\hline \multirow[t]{3}{*}{ Classe } & \multicolumn{6}{|l|}{ Área } \\
\hline & \multicolumn{2}{|l|}{2010} & \multicolumn{2}{|l|}{2014} & \multicolumn{2}{|l|}{2018} \\
\hline & $\left(\mathrm{Km}^{2}\right)$ & (\%) & $\left(\mathrm{Km}^{2}\right)$ & (\%) & $\left(\mathrm{Km}^{2}\right)$ & (\%) \\
\hline Vegetação Densa & 23,07 & 30,39 & 24,04 & 31,67 & 22,9 & 30,17 \\
\hline Vegetação Não Densa & 19,69 & 25,94 & 18,13 & 23,88 & 13,7 & 18,05 \\
\hline Corpo D’água & 14,25 & 18,77 & 14,14 & 18,63 & 16,1 & 21,21 \\
\hline Área Urbanizada & 12,56 & 16,55 & 14,02 & 18,47 & 19,7 & 25,96 \\
\hline Duna & 2,38 & 3,14 & 1,04 & 1,37 & 1,0 & 1,32 \\
\hline Faixa de Praia & 3,95 & 5,20 & 4,53 & 5,97 & 2,5 & 3,29 \\
\hline
\end{tabular}

É evidente a intensificação da urbanização nas áreas próximas à PA-444 e da ponte que liga a sede municipal à ilha do Atalaia, geralmente representada por grandes empreendimentos e loteamentos voltados para a população flutuante. Outra área de destaque refere-se à porção mais interna, próxima à entrada da cidade, com ocupação residencial e comercial, representada principalmente pela população local, que tende a migrar em virtude da especulação imobiliária nas regiões centrais do município.

Diversos estudos que abordam sobre a dinâmica da expansão urbana em zonas costeiras vêm evidenciando o adensamento da malha urbana em consequência do crescimento populacional dessas áreas (MELLO et al., 2013).

De acordo com Brito (2004), alguns fatores têm contribuído para esse comportamento de aceleração do processo de urbanização em Salinópolis, estes são: o aumento do fluxo da população flutuante, o aumento das residências de veraneio (segunda residência), o desenvolvimento da infraestrutura pelo Estado, o projeto Agro-Industrial de Salinópolis S/A (AGRISAL), a doação de terras públicas pelo governador Alacid Nunes, o crescente melhoramento da infraestrutura local e a instalação de grandes empreendimentos. 
As Áreas de Preservação Permanente (APP) (Lei N 12.651, de 25 de maio de 2012) da área de estudo, representadas principalmente pelos manguezais (classe de Vegetação Densa) e restingas (inclusas na classe de Vegetação Não Densa), apresentaram, no geral, uma tendência de redução. A classe de Vegetação Densa exibiu um leve aumento no ano de 2014 (aumento de 1,28\%), comparado ao de 2010, e uma leve redução, de 1,5\%, em 2018. Isso pode ser justificado, de acordo com Nascimento Junior et al. (2012), pela tendência de progradação na costa em períodos anteriores a 2014, que sugere a ocorrência de salinização nos cursos superiores do estuário, gerando ambientes propícios ao estabelecimento de manguezais. Já a redução evidenciada em 2018 reflete o aumento da urbanização, principalmente nas proximidades da ilha do Atalaia (RANIERI et al., 2015; RANIERI et al., 2016; BRAGA et al., 2019). Quanto às áreas de Vegetação Não Densa, em especial as restingas, a sua redução, em 7,89\%, se dá tanto pela ação humana sobre essas áreas, com os estabelecimentos de estruturas urbanas em regiões mais próximas às praias, como por fatores naturais (AMARAL et al., 2008).

\section{Análise dos questionários aplicados}

Os resultados das entrevistas com a população fixa de Salinópolis apresentam, no Bloco 1, informações associadas a fatos históricos, que auxiliam no entendimento da formação socioespacial da área em estudo. De acordo com Almeida (2017), a análise do período, forma e motivação da ocupação são válidos por permitir relacionar mudanças ocorridas durante o início do processo de ocupação do município com as que são visualizadas na atualidade.

O tempo de moradia em Salinópolis da maioria dos entrevistados, 68\%, é de mais de 15 anos, sendo $29 \%$ os moradores de 15 a 30 anos e $39 \%$ os que moram há mais de 30 anos, representando uma população antiga, que, em maior parte, sempre morou no município ou migrou há muitos anos.

O período de aquisição do espaço em uso (residência, segunda residência ou comércio) pode indicar o momento em que a região passou a receber incentivos ao desenvolvimento e urbanização. A evidência de residentes desde a década de 60 , mesmo que pouco representativa (3\%), indica o início do processo de urbanização, que foi se intensificando com o passar das décadas.

Ao comparar os resultados do tempo de moradia e período de aquisição do espaço em uso pode-se verificar que, apesar da maioria da população estar instalada no município há muito tempo, também a maioria adquiriu o espaço em uso nos últimos 20 anos, sendo $25 \%$ no período de 2000 e $30 \%$ no período de 2010, o que dá indícios de grande migração entre os bairros/regiões dentro do município, principalmente pela população que está em busca de imóveis mais baratos, visto a grande especulação imobiliária em algumas áreas, ou em busca de maior infraestrutura e segurança (ALMEIDA, 2017).

Quanto ao ambiente existente durante a aquisição do espaço em uso, 69\% dos entrevistados informaram que eram áreas de terra firme e $22 \%$ de mangue, representando bem a população fixa do município, visto que a população flutuante geralmente se direciona para áreas de praia, dunas e restinga, o que é confirmado pela motivação da aquisição do espaço que é para fins de residência (86\%). Além disso, a proporção de ambientes de terra firme no momento da aquisição do espaço reflete a preferência de 
ocupação em áreas mais estáveis do planalto costeiro.

Os resultados indicam que a ocupação no município não tem respeitado a legislação ambiental, tendo em vista que foi identificada a ocupação em Áreas de Preservação Permanente (APP) e praticamente inexistir a prestação de orientação técnica e fiscalização (82\%) para o estabelecimento de habitações na região.

Os resultados do Bloco 2 são os que mais fornecem informações acerca da dinâmica de ocupação do município e de suas variáveis explicativas. Neste bloco é possível observar em quais regiões ou bairros do município há maior tendência de ocupação e o que a motiva. Quanto à região/bairro de moradia dos entrevistados, os resultados mostraram uma boa distribuição da população, sendo os bairros/regiões de maior destaque os de São Vicente, São Tomé, São José, Ponta da Agulha, Guarani, Bom Jesus e Atlântico, considerados periféricos, e os de João Paulo II, Centro, Atalaia (incluindo as praias do Atalaia e Farol Velho), considerados centrais (Figura 3).

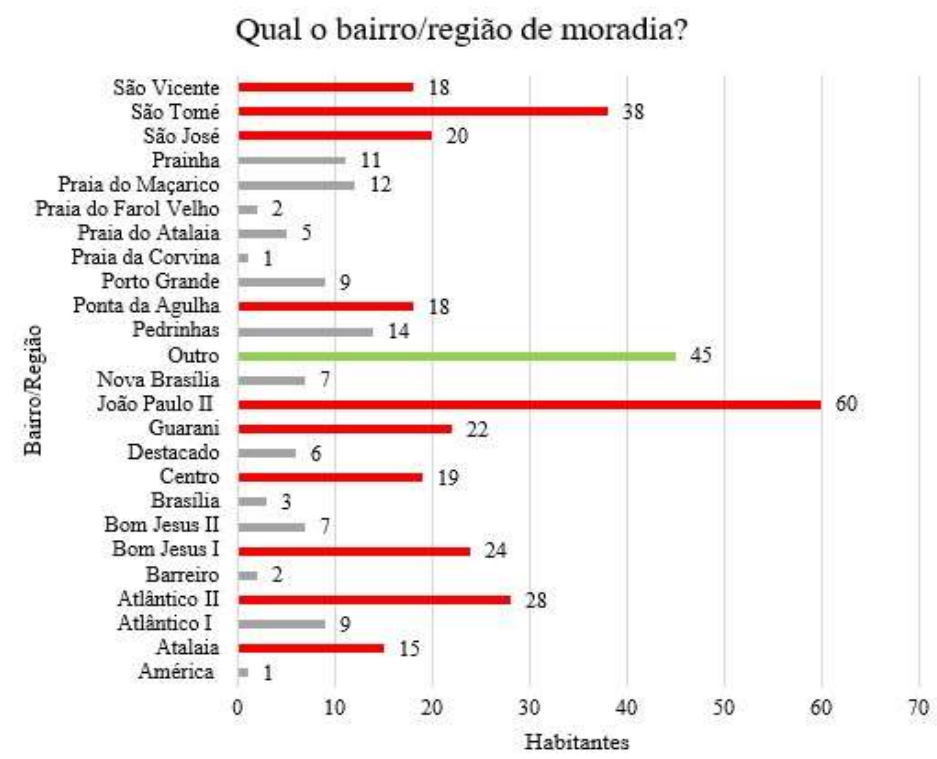

Figura 3: Bairro/região de moradia da população residente entrevistada. Vermelho = mais expressivo; Cinza = menos expressivo; Outro = pequenas comunidades, vilas e interiores próximos

Os resultados representam a população entrevistada, visto a predominância de ocupação em regiões centrais e comerciais do município e a pouca representatividade nas regiões da costa, tendo como principais motivações para aquisição do espaço em uso a familiar (39\%) e o imóvel mais barato (26\%). A motivação menos expressiva para os entrevistados foi a proximidade às praias (5\%). A parcela expressiva da população residente na ilha do Atalaia não representa uma população característica de veraneio, mas sim que se instala pela oportunidade de exercer atividades comerciais para a população flutuante durante os períodos de atividade turística.

A grande maioria dos entrevistados (91\%) não pretende se mudar para outro bairro/região, o que pode indicar uma baixa migração e evidencia a preferência pelos bairros/regiões onde vivem atualmente. Dentre os que estão dispostos a mudarem de residência (9\%), as regiões de maior preferência são os bairros Bom Jesus, Atlântico e Centro, sendo a busca por melhores serviços públicos (2\%), acessibilidade (2\%) e preço $(3,3 \%)$ as principais motivações. Apesar destes resultados não oferecerem informações acerca da dinâmica 
histórica ou atual de ocupação, são mais uma evidência da preferência por tais regiões.

Quanto à percepção da população acerca dos bairros/regiões preferenciais durante o processo de ocupação, 24 \% dos entrevistados não percebeu qualquer dinâmica da população local. Dentre o restante, os bairros percebidos como de maior preferência dos habitantes são os Bom Jesus, Atlântico, Atalaia e Centro, sendo a proximidade aos centros urbanos (43\%) e a presença de infraestrutura (26\%) os principais fatores que têm influenciado a busca por essas regiões.

O Bloco 3 de perguntas, relacionado aos aspectos ambientais, apresenta resultados referentes à percepção acerca de mudanças ambientais, que foi evidenciada por $92 \%$ dos entrevistados, dentre os quais foram observados, em ordem crescente de importância, expansão sobre áreas rurais, ocupação dos campos de dunas, ocupação de manguezais, urbanização das praias e construção de grandes obras. A categoria 'outros' são representadas por mudanças ambientais não associadas com a temática de estudo (Figura 4).

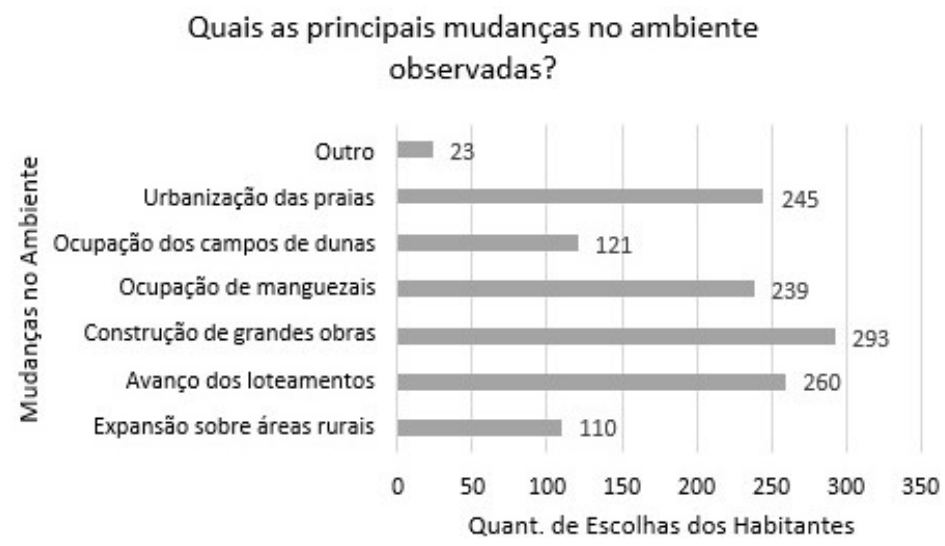

Figura 4: Principais mudanças observadas no ambiente de Salinópolis.

Apesar da grande presença do Estado quanto aos estímulos ao turismo na região, essas mudanças ambientais demonstram o impacto resultante da ausência dele quando se trata de infraestruturas básicas no município, proteção às APPs e ordenamento territorial. Isso evidencia a deficiência do planejamento turístico na região, gerando efeitos negativos ao ambiente e a insatisfação da população local.

Tal cenário, envolvendo o avanço da urbanização como resultado, sobretudo, da intensa atividade turística, também foi evidenciado por diversos estudos, a exemplo dos que embasaram o Quadro 2 (CAVALCANTE, 2001; BRITO, 2004; MARINHO, 2009; SOUZA, 2012; RANIERI, 2014; ALMEIDA, 2017). Pinheiro et al. (2020) destaca às alterações na estruturação e na organização espacial, associadas a implantação de melhorias urbanas de acesso e de circulação da cidade, assim como o crescente número de construtores prediais, sobretudo de segundas residências, como as principais mudanças paisagísticas que contribuem para a descaracterização do ambiente natural de Salinópolis.

As respostas obtidas nas entrevistas com os funcionários da prefeitura foram úteis tanto para a confirmação das informações e tendências apresentadas pelas entrevistas com a população residente, quanto para complementar de forma técnica dados da população e organização socioespacial nos últimos anos. Independente da secretaria entrevistada, as respostas foram semelhantes, o que permitiu comparálas e complementá-las. 
Os resultados das entrevistas foram analisados em quatro blocos temáticos (Quadro 1). Apesar do Bloco 2 ser o que mais traz informações acerca do comportamento da ocupação do município, os outros têm grande importância e são necessários para o entendimento do processo como um todo e para a discussão dos demais resultados, pois fornecem informações acerca da população total (fixa e flutuante) (Bloco 1), sobre as diretrizes impostas pela prefeitura para a ocupação (Bloco 3) e sobre como o município vê as questões ambientais (Bloco 4), temas fundamentais para o entendimento do contexto local.

Com base nos resultados do Bloco 1, as secretarias informaram a inexistência de um dado oficial sobre a quantidade da população flutuante do município em alta temporada. Ao serem questionadas acerca do acréscimo populacional nesses períodos, as secretarias apresentaram respostas divergentes, onde a Secretaria de Meio Ambiente não tem informação, a de Turismo afirma que a população, que hoje é de cerca de 40 mil habitantes, chega a dobrar, e a de Obras informa que está alcança um número entre 240 mil e 250 mil habitantes. A divergência ou mesmo ausência de informação acerca do volume populacional em dados períodos do ano é um fator que dificulta bastante o planejamento, a proposição de medidas de controle e a tomada de decisão do município, levando a gestões "individuais" das secretarias, que deveriam trabalhar de forma integrada.

Sabe-se que a população flutuante do município é mais expressiva que a população fixa durante os períodos de veraneio e feriados prolongados (BRITO, 2004; MARINHO, 2009; RANIERI, 2014), e isto é refletido na estrutura urbana do município, marcada por grande concentração de $2^{\circ}$ residências e empreendimentos destinados a essa população, que geralmente se concentram em regiões específicas.

De acordo com os resultados do Bloco 2, é unânime a identificação de regiões de preferência da população flutuante, e consequentemente de maior especulação imobiliária - áreas de praias, especialmente as da ilha do Atalaia, e ao bairro Destacado - e da população residente - regiões comerciais, do Centro e periferias, com predominância dos bairros do Atlântico e Bom Jesus, devido ao melhor preço dos imóveis, em função da menor especulação imobiliária, e presença de infraestrutura regular.

Quanto aos acontecimentos dos últimos anos que influenciaram na dinâmica de ocupação, tem-se a implantação de grandes empreendimentos e obras urbanas de incentivo à ocupação, principalmente na ilha do Atalaia, o que tem atraído a população pela geração de emprego e renda e também para a execução de atividades de comércio e serviço. Ao contrário dos outros representantes da prefeitura, o secretário de Obras acredita que a dinâmica de ocupação tem ocorrido dentro dos padrões esperados da expansão urbana, não sendo diretamente influenciada pela implantação de grandes empreendimentos e projetos urbanos.

Umas das principais obras urbanas que estimularam a ocupação da região foi a construção da PA444 e da ponte que liga a sede urbana à ilha do Atalaia (BRITO, 2004), fator que tem estimulado o crescimento e desenvolvimento comercial e especulação imobiliária das áreas próximas, gerando atrativos para a população flutuante. Além disso, visto o constante crescimento da região e estímulo ao turismo, que foi crescente desde a década de 30 até os dias atuais, existem projetos de novas obras de urbanização e grandes empreendimentos. Dentre as obras de urbanização têm-se a ampliação e restauração do Aeródromo de Salinópolis, construção da nova Rua do Linhão (novo acesso para entrada da cidade), além de obras de 
saneamento básico a serem estabelecidas nos bairros Bom Jesus e Atlântico. Quanto aos empreendimentos têm-se a conclusão do Aqualand Resort, a finalização do complexo de 5 Resorts (7 torres, sendo 4 já em operação, 2 em instalação e uma em fase de projeto) e a construção de dois parques aquáticos na ilha do Atalaia, os quais não foram divulgadas as empresas responsáveis.

As questões levantadas por este bloco mostram os eventos ocorridos nos últimos anos e os efeitos destes sobre a preferência de áreas pela população e pelo setor turístico. Os planos para novas obras e empreendimentos podem indicar um potencial de ocupação no seu entorno.

Os resultados do Bloco 3 trazem informações acerca das diretrizes, instrumentos legais e dos trâmites estabelecidos pela prefeitura para a construção nas regiões costeiras, sendo importante para visualizar até que ponto a gestão municipal está envolvida com o ordenamento territorial e preservação das áreas protegidas. Os principais instrumentos legais municipais para a gestão costeira pela secretaria de Meio Ambiente são o Plano Diretor do Município, a Política Municipal de Meio Ambiente (Lei Municipal º 2.848/2011) e outras Leis Municipais.

A secretaria de Turismo não tem informações sobre as diretrizes da expansão imobiliária ou dos trâmites e restrições impostos pela prefeitura, tendo em vista não estar envolvida com o processo de licenciamento das obras e empreendimento ou de controle de ordenamento. Pelo contrário, o papel deste setor é justamente estimular o turismo e a ocupação, contanto que obedeça às normas. Para isso, os principais instrumentos legais adotados são o Código de Postura do Município de Salinópolis (Lei $\mathrm{N}^{\circ}$ 2.058/2006) e normas relacionadas à organização de ambulantes.

A secretaria de Obras, por sua vez, afirma que a ocupação está ocorrendo de forma desordenada, em virtude de que a ocupação na faixa de praia é responsabilidade da Secretaria de Patrimônio da União (SPU), visto que as praias marítimas são consideradas bens da União (SPU, 2018), trazendo conflitos legais de controle e fiscalização. No entanto, com a promulgação da Lei $N^{\circ} 13.240 / 2015$ a União foi autorizada a transferir aos municípios interessados a gestão das praias marítimas urbanas com a finalidade de estabelecer uma gestão compartilhada. Essa transferência é condicionada pela assinatura de um termo de adesão pela União, solicitada a interesse do município, o que, até o momento da entrevista, não havia sido efetuada.

De acordo com o entrevistado, a prefeitura encontra dificuldade, principalmente, quando se trata de ocupação residencial, com destaque para a população de baixa renda, que acaba ocupando regiões periféricas, muitas vezes consideradas áreas impróprias e de risco.

Não há trâmites ou restrições impostas pela prefeitura para construções residenciais. Em raros casos (10\% a 15\%) o responsável pela construção residencial, por interesse próprio, procura a prefeitura para a regularização e atendimento às normas legais. A regularização, monitoramento e fiscalização destes imóveis por parte da prefeitura se torna inviável, visto o volume de residências do litoral e o corpo técnico reduzido das secretarias.

No entanto, quando se trata de empreendimentos, tanto a prefeitura quanto o próprio interessado estão envolvidos diretamente com o licenciamento, monitoramento e fiscalização. Para estes casos, o principal instrumento legal adotado pela secretaria de Obras é o Plano Diretor do Município de Salinópolis 
(Lei Municipal N².791/2006).

Quanto às diretrizes para a expansão imobiliária na zona costeira impostas pela secretaria de Meio Ambiente, a principal dificuldade se deve ao fato de que boa parte das construções são antigas, estabelecidas sem atendimento às normas, o que muitas vezes impede a reconstrução dentro dos padrões legais, cabendo à secretaria apenas o controle e fiscalização destas. Quando se trata de novas construções e empreendimentos, se busca realizar previamente e corretamente o processo de licenciamento e regularização, a fim de evitar danos futuros. Os trâmites e restrições impostos por esta secretaria para a construção no litoral segue o mesmo procedimento adotado pela secretaria de Obras, sendo a regularização de residências realizada a interesse do proprietário ( $10 \%$ a $15 \%$ dos casos), e de empreendimentos com o envolvimento direto do proprietário e prefeitura, acrescentado de fiscalizações de rotina. Essa questão mostra os efeitos da falta de planejamento urbano no passado e a ocupação desordenada que se instalou e tende a se propagar no município, caso ações de gestão mais eficazes não sejam estabelecidas.

O Bloco 4 traz à discussão o ponto de vista da prefeitura frente aos problemas ambientais e como o município está envolvido com planos de Unidades de Conservação (UCs). Apenas a secretaria de Meio Ambiente alegou reconhecer a presença de UC no município. Esta refere-se ao Monumento Natural Atalaia, criada pelo Decreto Estadual $N^{\circ} 2.077 / 2018$, que compreende uma área de 256,58 hectares na Ilha do Atalaia, mais especificamente no lago conhecido por Lago da Coca-Cola e suas proximidades, envolvendo ambientes de dunas, restingas, outros lagos e manguezais (Decreto Estadual $N^{\circ} 2.077$, de 23 de maio de 2018). Essa UC faz parte da categoria de Proteção Integral, de acordo com a Lei $n^{\circ} 9.985 / 2000$, que institui o Sistema Nacional de Unidades de Conservação (SNUC), sendo permitida apenas a realização de estudos e pesquisas científicas, ecoturismo, recreação e lazer, educação ambiental e conservação da natureza. $O$ órgão responsável por esta UC é o Instituto de Desenvolvimento Florestal e da Biodiversidade (Ideflor-Bio).

O não reconhecimento desta Unidade de Conservação pelas outras secretarias entrevistadas reflete a ausência de uma gestão integrada e de conhecimento legal e ambiental sobre as áreas do município, o que afeta consideravelmente o planejamento e a conservação da natureza, gerando diversos problemas ambientais e costeiros. Dentre estes problemas ambientais, a prefeitura tem identificado: ocupação desordenada; poluição ambiental de pousadas e restaurantes; erosão costeira; ocupação de áreas de risco de erosão e inundação; construção irregular em áreas de manguezais, a exemplo dos bairros Guarani, Atlântico e Carananzinho; e alagamento no bairro Porto Grande. Tais problemáticas também foram constatadas em estudo realizado por Pinheiro et al. (2020). Os autores destacam a importância de maiores ações em prol do meio ambiente, assim como no investimento de práticas de educação ambiental, como forma de sensibilizar os usuários quanto às questões ambientais em Salinópolis.

Por fim, a entrevista direcionada ao cartório do município foi útil ao confirmar as tendências de ocupação relatadas pela população residente e pelos funcionários da prefeitura envolvidos com o ordenamento territorial, e também pelos estudos bibliográficos e resultados indicados na análise espacial. De acordo com a titular cartorária entrevistada, a configuração espacial do município foi bastante definida pelos acontecimentos dos últimos 15 anos, no entanto é muito marcada pelos acontecimentos históricos, 
que levaram, na década de 1970, por exemplo, a uma intensificação de ocupação na região oeste do município, que posteriormente se direcionou para regiões centrais e próximas às praias, com destaque atualmente para a região do Atalaia quanto à sua atratividade turística e por receber grandes empreendimentos e obras de infraestrutura para facilitar o estabelecimento destes.

\section{Análise do modelo PEIR}

Os principais indicadores de pressão na área de estudo identificados incluem a: especulação imobiliária; o incentivo ao turismo; o desejo de áreas mais próximas à natureza e praias pela população flutuante e empresas imobiliárias e de vertente turística, como as de implantação de parques aquáticos; a busca por lotes mais baratos ou áreas de invasão pela população local, geralmente representados por bairros periféricos ou áreas impróprias e; busca por áreas de melhor infraestrutura e mais próximas aos centros urbanos tanto pela população local como pela flutuante (Quadro 3).

Quadro 3: Variáveis de pressão à dinâmica de ocupação da terra em Salinópolis (PA).

\begin{tabular}{|c|c|}
\hline Variável & Descrição \\
\hline Distância ao mar & $\begin{array}{l}\text { Medida a partir da linha da costa, considerada um elemento importante no processo histórico de } \\
\text { ocupação. }\end{array}$ \\
\hline $\begin{array}{l}\text { Distância às rodovias PA- } \\
444 \text { e PA-124 }\end{array}$ & $\begin{array}{l}\text { A proximidade às estradas é um fator explicativo da ocupação pois os agentes priorizaram áreas } \\
\text { de acesso facilitado. }\end{array}$ \\
\hline Densidade de malha viária & $\begin{array}{l}\text { Além de proximidade a estradas, a densidade de malha viária foi considerada indicativo do grau } \\
\text { de urbanização, influenciando na escolha do espaço para novas construções urbanas. }\end{array}$ \\
\hline $\begin{array}{l}\text { Distância às áreas de maior } \\
\text { especulação imobiliária }\end{array}$ & $\begin{array}{l}\text { Este vetor sintetiza a influência da proximidade às áreas de maior interesse econômico no } \\
\text { município. Essas áreas são: Ilha do Atalaia, Bairro do Destacado e Orla do Maçarico. }\end{array}$ \\
\hline $\begin{array}{l}\text { Grau de implantação de } \\
\text { empreendimentos }\end{array}$ & $\begin{array}{l}\text { Esses empreendimentos serão: resorts, grandes hotéis, parques aquáticos e grandes condomínios } \\
\text { litorâneos. }\end{array}$ \\
\hline $\begin{array}{l}\text { Distância às manchas } \\
\text { urbanas consolidadas }\end{array}$ & $\begin{array}{l}\text { Reflete a tendência de concentração das novas ocupações urbanas em relação às ocupações já } \\
\text { existentes. }\end{array}$ \\
\hline $\begin{array}{l}\text { Distância às áreas de menor } \\
\text { especulação imobiliária }\end{array}$ & $\begin{array}{l}\text { Essas áreas geralmente são uma das principais opções da população local de média e baixa renda } \\
\text { para expansão urbana. Normalmente são representadas por bairros periféricos. Essas áreas são: } \\
\text { bairros do Atlântico I, Atlântico II, Bom Jesus I, Bom Jesus II, São Tomé, Guarani e São José. }\end{array}$ \\
\hline $\begin{array}{l}\text { Distância ao centro } \\
\text { comercial }\end{array}$ & $\begin{array}{l}\text { As áreas centrais onde está instalada a maior parte do comércio da região, a exemplo dos bairros } \\
\text { do Centro e João Paulo II, possuem grande interesse pela população local, visto a atratividade por } \\
\text { infraestrutura, postos de trabalho e para interesses de implantação de atividades comerciais. }\end{array}$ \\
\hline
\end{tabular}

O estado atual do ambiente na região reflete as pressões e indução de ocupação sobre a área de estudo e evidencia: a concentração de grandes empreendimentos na llha do Atalaia; grande quantidade de $2^{\circ}$ residências, principalmente próximas às praias do Atalaia, Farol Velho e Maçarico, com destaque para o bairro do Destacado; ocupação de dunas e próxima e sobre a linha de costa, obrigando o estabelecimento de contenções particulares de erosão costeira em residências; avanço de obras urbanas sobre manguezais, a exemplo da obra de duplicação da PA-444, que liga o município à Ilha do Atalaia; expansão urbana próxima à entrada da cidade e ao longo da PA-124 e PA-444; concentração urbana e intensa movimentação de pessoas próxima aos centros comerciais; ocupação de bairros periféricos e; a presença de regiões com movimentação apenas em períodos de alta temporada turística e que durante o resto do ano são pacatas, como em áreas próximas à Orla do Maçarico e em boa parte da Ilha do Atalaia (Figura 5). 


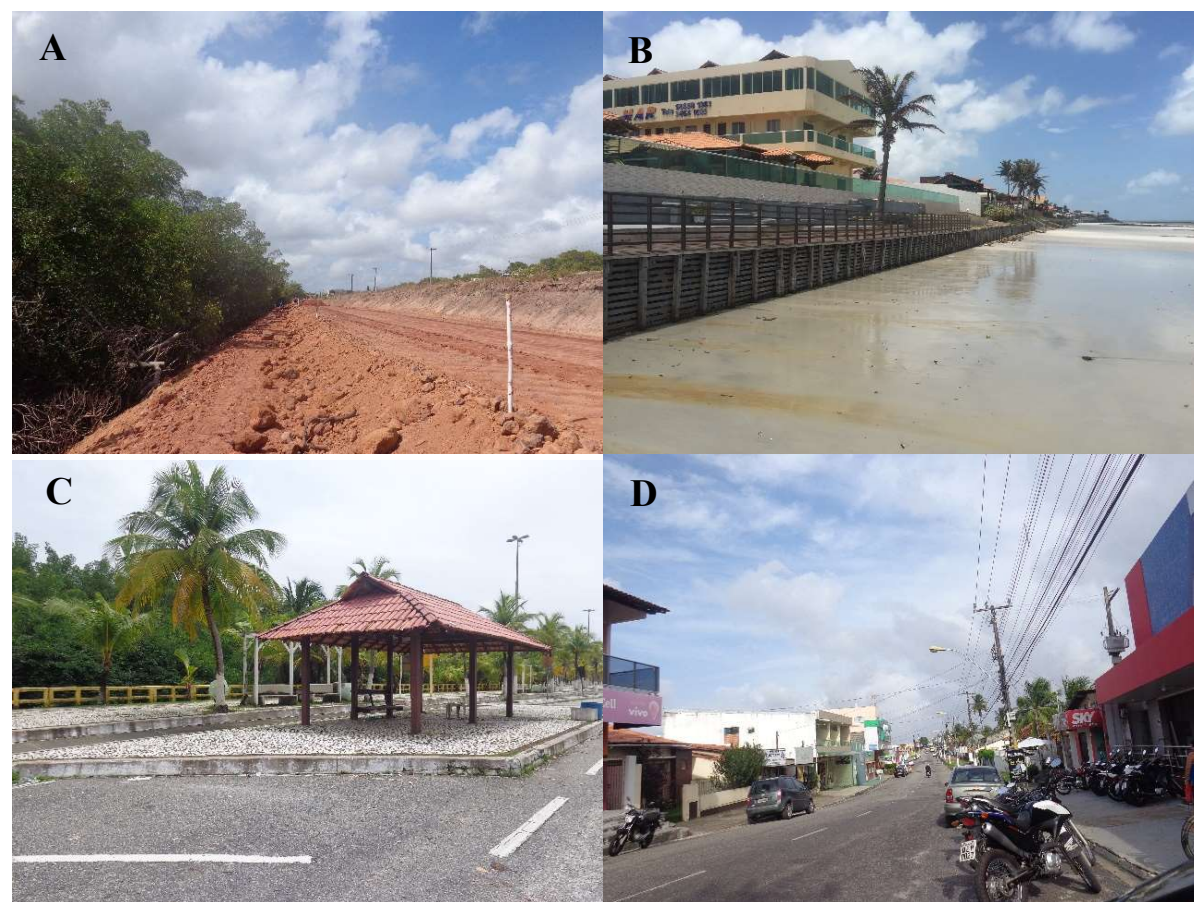

Figura 5: Exemplos do estado atual do ambiente em Salinópolis/PA. A) Duplicação da PA-444 e avanço sobre áreas de manguezais; B) Ocupação sobre a linha de costa - Ilha do Atalaia; C) Regiões com movimentação apenas em alta temporada - Orla do Maçarico; e D) Centro comercial.

Os impactos, por sua vez, representam as consequências das mudanças do estado do ambiente. Os principais impactos observados na área de estudo foram: a segregação socioespacial; a modificação e ocupação de ecossistemas como áreas de manguezais, dunas e restingas; potencialização da erosão costeira, principalmente nas praias do Farol Velho e Atalaia; economia sazonal; ocupação desordenada e; saneamento ineficiente nas regiões periféricas.

Tal realidade também foi constatada por outros estudos na região (SOUZA, 2012; RANIERI et al., 2015; ALMEIDA, 2017; PINHEIRO et al., 2020), o que evidencia a grande importância da criação de ações que busquem a resolução desta problemática socioambiental.

As respostas da sociedade frente às pressões e impactos sobre o estado do ambiente referem-se: à migração para áreas de menor especulação imobiliária pela população local; intensificação de ocupação em áreas centrais e próximas às praias; intensificação da implantação de grandes obras urbanas e empreendimentos para atender o turismo; implantação de atividades de comércio e serviços pela população local para atender o público flutuante, ficando em inatividade ou reduzindo drasticamente o rendimento durante os períodos de baixa temporada e; recuo, modificação e adaptação de estruturas físicas instaladas próximas à linha de costa que têm sido afetadas pela erosão costeira.

Como foi observado ao longo do trabalho, a maioria dessas respostas estão associadas geograficamente às regiões próximas às praias. Braga et al. (2019), ao realizarem o levantamento do Índice de Vulnerabilidade Costeira (IVC) para o município de Salinópolis, baseado nas variáveis de geomorfologia, declividade da costa, cota topográfica, altura da onda, amplitude de maré, taxa de erosão e nível do mar, observaram que essas regiões se destacam quanto ao seu IVC, principalmente o setor da praia do Atalaia (Praia do Atalaia: IVC Alto; Praias do Farol Velho, Maçarico e Corvina: IVC Moderado). De acordo com os autores, a região desta praia possui IVC Alto, em virtude da alta ocupação urbana em Zona Costeira de Baixa 
Elevação, onde, por exemplo, o aumento de um metro do nível do mar, associado com as altas amplitudes de marés, aumentarão a frequência de inundações e erosões. Por isso está é uma das regiões de maior preocupação na área de estudo e que deve receber mais atenção da gestão local.

Essas respostas são uma reação aos indicadores de pressão, estado e impacto, no entanto também são consideradas ações sobre os mesmos indicadores, que podem refletir na atenuação ou anulação dos impactos ambientais, caso medidas de correção e prevenção sejam tomadas, ou mesmo na intensificação destes, caso nenhuma medida seja tomada (Figura 6).

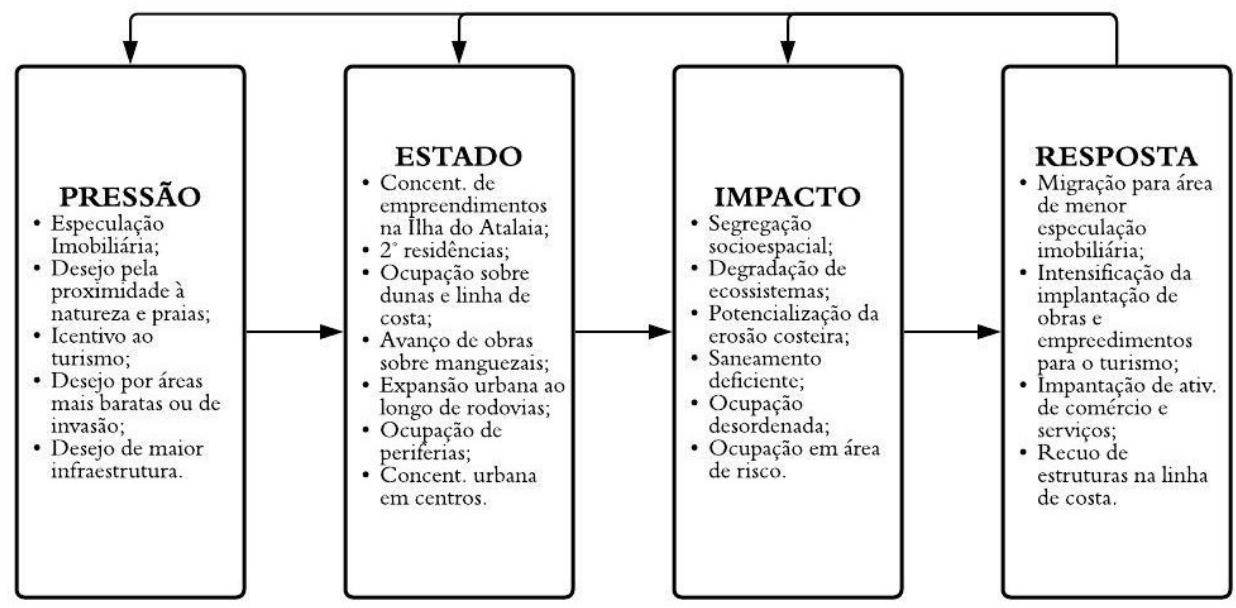

Figura 6: Aplicação do modelo PEIR na análise de ocupação da área de estudo.

Parte dos resultados observados na figura anterior também foram identificados por outros autores que utilizaram modelos próximos de análise em diferentes localidades (PALMER et al., 2011; GEDEFAW et al., 2020; MANDIC, 2020). Qu et al. (2020) ao analisarem a interação entre a expansão do solo e a política de uso do solo através de um modelo próximo. Concluíram que as políticas de uso do solo devem levam em consideração a complexidade e sistematicidade da expansão do uso do solo em consideração para a gestão do solo urbano.

\section{CONCLUSÕES}

O município de Salinópolis teve os primeiros movimentos de ocupação em 5.000 anos antes do presente, no entanto os efeitos da urbanização passaram a ser observados com maior atenção no século XX, especialmente a partir da década de 30 , quando iniciaram os primeiros empreendimentos e obras de urbanização para atender o potencial turístico local. Com o passar das décadas esse potencial passou a ser intensamente explorado e incentivado pelo Estado. Isso é refletido na grande concentração de segundas residências, grande especulação imobiliária em algumas regiões e grandes obras urbanas, especialmente na ilha do Atalaia, em áreas próximas à Orla do Maçarico e no bairro Destacado.

Apesar da grande presença do Estado nos incentivos ao turismo na região, este se mostra ausente quando se tratam das necessidades da população residente, que crescentemente tem migrado para áreas de menor especulação imobiliária, bairros de periferia e invasão, com saneamento básico deficiente, e também ocupando áreas de risco. A região central do município é de grande interesse tanto para a população 
flutuante, que busca conforto e acesso facilitado ao comércio e serviços, quando para a população residente, na busca por infraestrutura, postos de trabalho e na tentativa de implantar atividades de comércio e serviços. Em todos os casos, o movimento de ocupação veio acompanhado de impactos ao meio ambientes, como a ocupação de áreas protegidas, danos aos ecossistemas, erosão costeira e poluição por resíduos sólidos.

A aplicação do modelo PEIR auxiliou na interpretação dos indicadores de pressão que implicam no estado do ambiente da área de estudo, causando impactos, que são refletidos em respostas da sociedade quando à ocupação da terra no município. Além disso, permitiu o levantamento das principais variáveis que explicam a dinâmica de ocupação em Salinópolis, que são: distância ao mar; distância às rodovias PA-444 e PA-124; densidade de malha viária; distância às áreas de maior especulação imobiliária; grau de implantação de empreendimentos; distância às manchas urbanas consolidadas; distância às áreas de menor especulação imobiliária; e distância ao centro comercial.

AGRADECIMENTOS: Agradecimento aos alunos de iniciação científica do Laboratório de Modelagem Hidroclimática e de Cobertura da Terra na Amazônia - LabHCAM da Universidade Federal Rural da Amazônia - UFRA pelo apoio na aplicação dos questionários em Salinópolis-PA.

\section{REFERÊNCIAS}

ALMEIDA, A. F.. Os efeitos das políticas públicas de desenvolvimento socioeconômico na zona costeira do nordeste paraense: expansão rodoviária, urbanização e atividade turística. Tese (Doutorado em Ciências Ambientais) - Universidade Federal do Pará, Belém, 2017.

ALVES, C. D.; PEREIRA, M. N.; FLORENZANO, T. G.; SOUZA, I. M.. Análise orientada a objeto no mapeamento de áreas urbanas com imagens Landsat. Boletim de Ciências Geodésicas, Curitiba v.15, n.1, p.120-141, 2009.

AMARAL, D. D.; PROST, M. T.; BASTOS, M. N. C.; COSTA NETO, S. V.; SANTOS, J. U. M.. Restingas do litoral amazônico, estados do Pará e Amapá, Brasil. Bol. Mus. Para. Emílio Goeldi. Ciências Naturais, Belém, v.3, n.1, p.35-67, 2008.

ANTOCHEVIZ, F. B.. Análise multiescalar da expansão urbana de cidades litorâneas. In: ENCONTRO NACIONAL DA ASSOCIAÇÃO NACIONAL DE PÓS-GRADUAÇÃO E PESQUISA EM PLANEJAMENTO URBANO E REGIONAL, 17. Anais. São Paulo: ANPUR, 2017. p.1-20.

AREND, M.; FONSECA, P. C. D.. Brasil (1955-2005): 25 anos de catching up, 25 anos de falling behind. Revista de Economia Política, São Paulo, v.32, n.1, p.33-54, 2012.

BAATZ, M.; BENZ, U.; DEHGHANI, S.; HEYNEN, M.; HÖLTJE, A.; HOFMANN, P.; LINGENFELDER, I.; MIMLER, M.; SOHLBACH, M.; WEBER, M.; WILLHAUCK, G.. e-Cognition Professional User Guide 4. München: Definiens Imaging $\mathrm{GmbH}, 2004$

BAATZ, M.; SCHÄPE, A.. Multiresolution segmentation: an optimization approach for high quality multi-scale image segmentation. In: STROBL, J.; BLASCHKE, T.; GRIESBNER, G.. Angewandte Geographische Informations verarbeitung. Karlsruhe: Herbert Wichmann Verlag, 2000. p.12-23.
BARROS, A. J. P.; LEHFELD, N. A. S.. Projeto de pesquisa: propostas metodológicas. 5 ed. Petrópolis: Vozes, 1997.

BRAGA, R. C.; PIMENTEL, M. A. S.. Índice de vulnerabilidade diante da variação do nível do mar na Amazônia: estudo de caso no município de Salinópolis-Pará. Revista Brasileira de Geografia Física, Recife, v.12, n.02, p.534-561, 2019. DOI: http://doi.org/10.26848/rbgf.v12.2.p534-561

BRITO, F. M. O.. Salinópolis-PA: (Re) Organização Socioespacial de um Lugar Atlântico-Amazônico. Dissertação (Mestrado em Geografia) - Universidade Federal de Santa Catarina, Florianópolis, 2004.

CAVALCANTE, F. C.. Migração e ocupação nos espaços periféricos da zona costeira do Estado do Pará: o caso do município de Salinópolis. In: CONGRESSO DA ASSOCIAÇÃO BRASILEIRA DE ESTUDOS DO QUATERNÁRIO. 10. Anais. Guarapari: ABEQUA, 2001. p.1-6.

FURTADO, L. F. G.. Ocupação humana do litoral amazônico. In: PROST, M. T. R. C.; MENDES, A.. Ecossistemas costeiros: impactos e gestão ambiental. Belém: MPEG, 2011. p.220.

FURTADO, L. F. G.; NASCIMENTO, I. H.. Traços de uma comunidade pesqueira do litoral Amazônico: relato sobre organização em comunidade haliêutica. In: FURTADO, L. F. G.; QUARESMA, H. D. A. B.. Gente e ambiente no mundo da pesca artesanal. Belém: MPEG, 2002. p.258.

GARI, S. R.; NEWTON, A.; ICELY, J. D.. A review of the application and evolution of the DPSIR framework with an emphasis on coastal social-ecological systems. Ocean Coast. Manag., v.103, p.63-77, 2015.

GEDEFAW, A. A.; ATZBERGER, C.; BAUER, T.; AGEGNEHU, S. K.; MANSBERGER, R.. Analysis of land cover change detection in Gozamin district, Ethiopia: From remote sensing and DPSIR perspectives. Sustainability, v.12, n.11, p.4534, 2020. DOI: http://doi.org/10.3390/su12114534 
GLEYZES, J. P.; MEYGRET, A.; FRATTER, C.; PANEM, C.; BAILLARIN S.; VALORGE, C.. SPOT5: system overview and image ground segment. In: GEOSCIENCE AND REMOTE SENSING SYMPOSIUM, 3. Anais. Toulouse: IGARSS, 2003. p.300-302.

GOODE, W. J.; HATT, P. K.. Métodos em pesquisa social. 7 ed. São Paulo: Nacional, 1979.

HUETE, A. R.. A Soil-Adjusted Vegetation Index (SAVI). Remote Sensing of Environment, Amsterdam, v.25, n.3, p.205-309, 1988

IBGE. Instituto Brasileiro de Geografia e Estatística. Estimativas da população residente com data de referência 10 de julho de 2019. Diretoria de Pesquisas, Coordenação de População e Indicadores Sociais. IBGE, 2020.

MANDIĆ, A.. Structuring challenges of sustainable tourism development in protected natural areas with driving forcepressure-state-impact-response (DPSIR)

framework. Environment Systems and Decisions, p.1-17, 2020. DOI: http://doi.org/10.1007/s10669-020-09759-y

MARINHO, R. S.. Faces da expansão urbana em Salinópolis, zona costeira do Estado do Pará. Dissertação (Mestrado em Geografia) - UniversidadeFederal do Pará, Belém, 2009.

MELLO, K.; TOPPA, R. H.; ABESSA, D. M. S.; CASTRO, M. Dinâmica da expansão urbana na zona costeira brasileira: o caso do município de São Vicente, São Paulo, Brasil. Revista Gestão Costeira Integrada, Lisboa, v.13, n.4, p.539-551, 2013. DOI: http://doi.org/10.5894/rgci432

NASCIMENTO JUNIOR, W. R.; SOUZA FILHO, P. W. M.; PROISY, C.; LUCAS, R. M.; ROSENQVIST, A.. Mapping changes in the largest continuous Amazonian mangrove belt using object-based classification of multisensor satellite imagery. Estuarine, Coastal and Shelf Science, p.1-11, 2012. DOI: http://dx.doi.org/10.1016/i.ecss.2012.10.005

PALMER, B. J.; HILL, T. R.; MCGREGOR, G. K.; PATERSON, A. W.. An assessment of coastal development and land use change using the DPSIR framework: case studies from the Eastern Cape, South Africa. Coastal Management, v.39, n.2, p.158-174, 2011.

PINHEIRO, C. P. S.; ROSA, A. G.; SOUSA, A. M. L.. Análise dos impactos socioambientais na zona costeira do município de Salinópolis/PA. DRd - Desenvolvimento Regional em Debate, v.10, p.222-244, 2020. DOI: http://doi.org/10.24302/drd.v10i0.2553

PINTO, R.; JONGE, V. N.; NETO, J. M.; DOMINGOS, T.; MARQUES, J. C.; PATRÍCIO, J.. Towards a DPSIR driven integration of ecological value, water uses and ecosystem services for estuarine systems. Ocean Coast. Manag. v.72, p.64-79, 2013. DOI:

http://doi.org/10.1016/j.ocecoaman.2011.06.016

PLANET. Planet Imagery Product Specification: Planetscope \& Rapideye. 2017.
QU, S.; HU, S.; LI, W.; WANG, H.; ZHANG, C.; LI, Q.. Interaction between urban land expansion and land use policy: An analysis using the DPSIR framework. Land Use Policy, v.99, n.104856, 2020. DOI:

http://doi.org/10.1016/j.landusepol.2020.104856

RANIERI, L. A.. Morfodinâmica costeira e o uso da Orla Oceânica de Salinópolis (Nordeste do Pará, Brasil). Tese (Doutorado em Geologia e Geoquímica) - Universidade Federal do Pará, Belém, 2014.

RANIERI, L. A.; EL-ROBRINI, M.. Condição oceanográfica, uso e ocupação da Costa de Salinópolis (Setor Corvina - Atalaia), Nordeste do Pará, Brasil. Revista de Gestão Costeira Integrada, Porto, v.16, n.2, p.133-146, 2016. DOI: http://doi.org/10.5894/rgci565

RANIERI, L. A.; EL-ROBRINI, M.. Evolução da linha de costa de Salinópolis, Nordeste do Pará, Brasil. Pesquisas em Geociências, Porto Alegre, v.42, n.3, p.207-226, 2015. DOI: http://doi.org/10.22456/1807-9806.78121

RAPIDEYE. Satellite imagery product specifications. PLANET, 2016.

SALLES, M. C. T.; GRIGIO, A. M.; SILVA, M. R. F.. Expansão urbana e conflito ambiental: uma descrição da problemática do município de Mossoró, RN - Brasil. Soc. \& Nat. Uberlândia, v.25, n.2, p.281-290, 2013. DOI: http://doi.org/10.1590/S1982-45132013000200006

SANTANA, G.. Formas organizativas e estratégias de vida no litoral paraense. In: PROST, M. T. R. C.; MENDES, A.. Ecossistemas costeiros: impactos e gestão ambiental. Belém: MPEG, 2011.

SOUSA-FELIX, R. C. S.; PEREIRA, L. C. C.; TRINDADE, W. N.; SOUZA, I. P.; COSTA, R. M.; JIMENEZ, J. A.. Application of the DPSIR framework to the evaluation of the recreational and environmental conditions on estuarine beaches of the Amazon coast. Ocean \& Coastal Management, v.149, p.96106, 2017. DOI: https://doi.org/10.1016/j.ocecoaman.2017.09.011

SOUZA, G. B. N.. Uso do solo da llha do Atalaia no Município de Salinópolis (PA): desafios para o reordenamento territorial. Dissertação (Mestrado em Gestão dos Recursos Naturais e Desenvolvimento Local na Amazônia, Núcleo de Meio Ambiente) - Universidade Federal do Pará, Belém, 2012.

SOUZA, G. B. N.; ROCHA, G. M.. Ordenamento territorial na ilha do Atalaia, Salinópolis (PA): uma análise a partir dos diferentes trechos de ocupação. Revista do Instituto Histórico e Geográfico do Pará, Belém, v.05, n.01, p.137151, 2018.

SPU. Secretaria do Patrimônio da União. Manual de Fiscalização do Patrimônio da União. Ministério do Planejamento, Desenvolvimento e Gestão, 2018.

ZAR, J. H.. Biostatistical Analysis, 3. ed. New Jersey: Prentice Hall, 1996.

A CBPC - Companhia Brasileira de Produção Científica (CNPJ: 11.221.422/0001-03) detém os direitos materiais desta publicação. Os direitos referem-se à publicação do trabalho em qualquer parte do mundo, incluindo os direitos às renovações, expansões e disseminações da contribuição, bem como outros direitos subsidiários. Todos os trabalhos publicados eletronicamente poderão posteriormente ser publicados em coletâneas impressas sob coordenação da Sustenere Publishing, da Companhia Brasileira de Produção Científica e seus parceiros autorizados. Os (as) autores (as) preservam os direitos autorais, mas não têm permissão para a publicação da contribuição em outro meio, impresso ou digital, em português ou em tradução. 